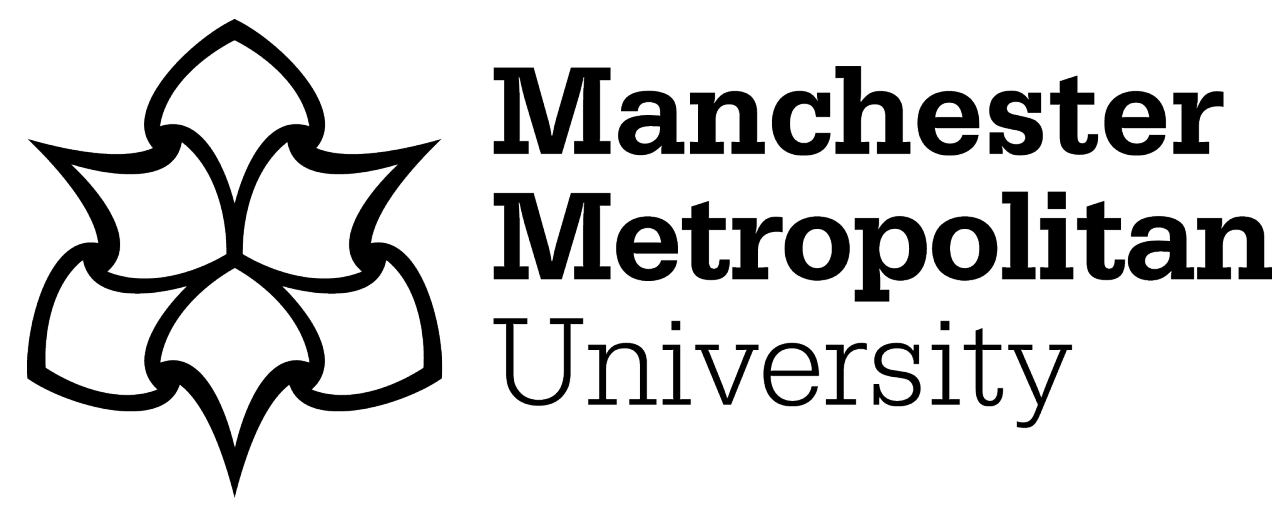

Urquhart, C ORCID logoORCID: https://orcid.org/0000-0001-7754-6085 (2016) Response to Davison and Martinsons: Context is King! Yes and No It's Still All About Theory Building. Journal of Information Technology, 31 (3). pp. 254-256. ISSN 0268-3962

Downloaded from: https://e-space.mmu.ac.uk/60/

Version: Accepted Version

Publisher: SAGE Publications

DOI: https://doi.org/10.1057/s41265-016-0002-x

Please cite the published version 


\title{
Response to Davison and Martinsons: Context is King! Yes and no - it's still all about theory (building)
}

\author{
Cathy Urquhart
}

Department of Marketing, Operations and Digital Business, Manchester Metropolitan University Business School, All Saints Campus, Oxford Road, Manchester, M15 6BH, United Kingdom

Davison and Martinsons breathe some fresh air into the 'Is Theory King' debate that has enlivened JIT of late (Avison and Malaurent 2014, Markus 2014, Lee 2014, Gregor 2014), by drawing our attention to the important issue of context, and its relationship to theory. They make two major points; first, that often IS researchers treat theories they use in a universalist manner - that is, the context and boundary conditions of the theory being used is commonly ignored. Secondly, by taking a cultural view of context, they make the compelling argument that, in an increasingly globalised world, that the context of locally distinctive values and behaviours will become more important. They suggest two prescriptions: first, that we avoid simplistic research and consider cultural and institutional constraints as part of the research design process; second, that editors and reviewers consider that they have an obligation to understand the context of the research they are evaluating. They then conclude with a clarion call for a much more nuanced understanding of context and theory validation.

So, then, what are we to make of as a community this call to consider context? My first reaction, as a grounded theorist, was to object to the idea of a dichotomy between universalism and particularism. Surely, there are levels of theory, ranging from seed concepts to formal theory (Urquhart, Lehmann and Myers 2010), as illustrated below. That said, one of the outcomes of the Is Theory King debate was

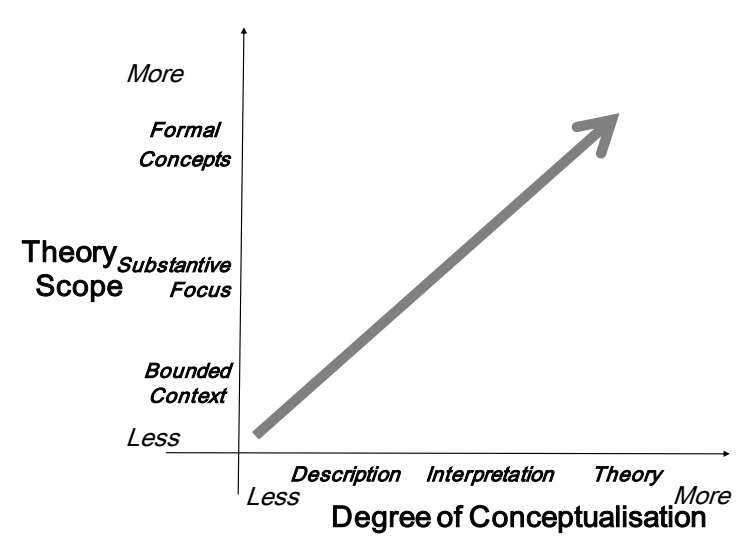
a view from Lee (2014) and Markus (2014) that, in our discipline, that there is a lack of consensus as to what theory actually is. So, while it is undoubtedly true that there is a rush to generalise to populations, rather than to theory (Yin 1994), this call to consider context seems to be an aspect of the same problem. So, why does this rush to universalism occur? Perhaps we overrate the idea of novelty and new contribution, and don't think enough about justification and replication. In the rush to claim a contribution, and get published, there is the temptation to overclaim. We seem as researchers not to see ourselves as part of a more unified theory building effort, where we can apply a nascent theory to different settings with different boundary conditions.

I've examined the challenge of theory generalisation from a grounded theory standpoint in qualitative research (Urquhart 2013). The founders of grounded theory (Glaser and Strauss, 1967) well understood the issue of context, and how it relates to generalisation and abstraction. Their first suggestion is the 'rewrite' method, where the theory is rewritten to omit specifics of the setting, to make it more abstracted. This effectively strips away context, in pursuit of the very universalism that 
Davison and Martinsons object to. That said, they also make recommendations as to how to move substantive theory to formal theory, by first minimising and maximising group differences, and also considering the diversity or similarity of coded concepts within those groups. Eisenhardt (1989) also suggests the use of like and unlike groups in theory building when using case studies.

What all these recommendations have in common is an acute understanding of different settings and boundary conditions, and it seems odd that our discipline does not really discuss these issues in the same way. We seem not to explicitly acknowledge that theory can shade from bounded contexts, through to substantive theory (pertaining to the phenomena being studied) through to more formal concepts. As a discipline, we seem not to include a consideration of what a theory is, its shape and form, and its characteristics, in our research training of new researchers. We leave little room for our research trainees to become 'theoretically sensitive' in Glaser's (1978) terminology. Ideally our trainee researchers should be taught to recognise the vast range of different theories that exist, how those theories might describe relationships between constructs, and crucially, for what purpose theories might be developed (Gregor 2006). Burton-Jones (2014) makes an excellent contribution to the IS theory debate when he suggests moving away from ideas of process/variance theories towards conceptual latitude and fit, and focusing on constructs and relationships.

I would heartily agree with Davison and Martinsons' call for context to be explicitly considered in research design, and for researchers to consider the scope of validity. Their final line is to me the most compelling - 'Theory can then be tested and validated in different contexts'. It would be tremendously helpful if editors and reviewers helped authors to frame what theory building - or theory testing contribution they might be intending to make, and for those authors to seriously consider the scope of their theory. These recommendations might help bring together the fragmented theory building effort that seems to exist in our discipline currently.

Another key contribution of Davison and Martinsons' article is their contention that consideration of context becomes ever more important in an increasingly interconnected globalised world. They make the point that the effectiveness of policies and practices depend on rigorous research in relevant contexts, and that the impact of IT will often depend critically on the context. This has long been an issue in ICT for development research. Walsham (2005) pointed out that ICTs were initially developed in the rich countries of the world, so they reflect to some extent the cultures and lifestyles of those countries. At worst then, we in the IS discipline can be guilty of an unthinking colonialism - which can be obviated by care and attention to context. Their point about the role of language in ICTs is well taken - while English is the 'lingua franca', they say this is a matter of convenience rather than genuine linguistic convergence. The lingua franca can itself be seen as a tool for cultural dominance (Diaz Andrade and Urquhart 2009), so we should all be sensitive to ICTs role in the world, given their frequent transmission of Western assumptions and the English language. Davison and Martinsons are to be thanked for their thoughtful and timely article, which helps us ponder better ways of understanding the role of context, both in terms of theory scope, and the need to be sensitive to the cultural settings we find ourselves researching in. 


\section{References}

Avison D, and Malaurent J (2014) Is Theory King? : Questioning the Theory Fetish in Information Systems, Journal of Information Technology, 29, 327-336

Burton-Jones A, McLean E, and Monod E (2014), Theoretical Perspectives on IS Research: From Variance and Process to Conceptual Latitude and Fit, European Journal of Information Systems, 00, 116

Diaz Andrade, A. and Urquhart, C. (2009), ICTs as a Tool for Cultural Dominance: Prospects for a Twoway Street, Electronic Journal of Information Systems in Developing Countries, 15 (2), 108-132

Eisenhardt, K. M. (1989). Building theories from case study research. Academy of management review, 14(4), 532-550.

Glaser, B. G. (1978). Theoretical Sensitivity: Advances in the Methodology of Grounded Theory. Mill Valley, CA: The Sociology Press.

Glaser, B. G., and Strauss, A. L. (1967). The Discovery of Grounded Theory: Strategies for Qualitative Research. Chicago: Aldine Publishing Company

Gregor S (2014) Theory - Still King but Needing a Revolution!, Journal of Information Technology, 29, $337-340$

Lee A S (2014) Theory is King? But First, What is Theory? Journal of Information Technology, 29, 350352

Markus LM (2014) Maybe not the King, but an invaluable subordinate: A Commentary on Avison and Malaurent's advocacy of 'Theory Light' IS Research, Journal of Information Technology, 29, 341-345

Urquhart, C. (2013). Grounded Theory for Qualitative Research: A Practical Guide. London: Sage

Urquhart, C., Lehmann, H., and Myers, M. D. (2010). Putting the 'Theory' Back into Grounded Theory: Guidelines for Grounded Theory Studies in Information Systems. Information Systems Journal, 20(4), 357-381

\section{About the Author}

Cathy Urquhart is Professor of Digital and Sustainable Enterprise at MMU Business School. She is an Editorial Board member for the Information Systems Journal and Information Technology and Development. She has published in many IS journals such as the Journal of the Association of Information Systems, the European Journal of Information Systems, Journal of Information Technology, Information Systems Journal, and others. Her research interests include the use of digital innovation for societal good, and also grounded theory. Her 2013 book on grounded theory, published by Sage, is called Grounded Theory for Qualitative Research: A Practical Guide. Her website can be found here http://www.business.mmu.ac.uk/our-staff/modb/profile/index.php?profile id=899 and her email address is c.urquhart@mmu.ac.uk 